\title{
CARCINOMATOSE DAS MENINGES
}

\author{
DADOS CLÁNICO-PATOLÓGICOS DE 3 CASOS
}

\author{
Aristides Cheto DE Queiroz * \\ Carlos Renato Melo **
}

O termo carcinomatose das meninges tem sido empregado por vários autores para designar o envolvimento metastático difuso das meninges cerebrais e/ou raqueanas, geralmente na ausência de nódulos neoplásicos macroscópicos disseminados pela substância nervosa $4,5,8$. Outros termos têm sido utilizados para designar a condição, como meningite carcinomatosa ${ }^{1,16}$ e até mesmo encefalite carcinomatosa, este último reservado para aquela situação em que, além do envolvimento das meninges, também o parênquima e espaços perivasculares são envolvidos, sem a formação de nódulos ${ }^{10}$. A carcinomatose das meninges constitui uma forma rara de disseminação dos carcinomas, tendo sido motivo de publicações como casos isolados ${ }^{5,9}$ ou como pequena série de $\operatorname{casos}^{4}, 12,13$.

Este relato de 3 casos tem por finalidade chamar atenção para uma condição que aparece como um comprometimento neoplásico difuso das meninges, associado a um quadro neurológico proeminente, superponível ao das meningites de curso crônico ou das encefalomielites.

\section{MATERIAL E METODOS}

Foram estudados 3 casos de carcinomatose das meninges observados no material de autópsia do Hospital Professor Edgard Santos, da Universidade Federal da Bahia, no período de agosto de 1970 a abril de 1974. Os prontuários clínicos foram consultados para avaliação do quadro neurológico e dados de exame do líquido cefalorraqueano. Todos os casos foram submetidos à autópsia completa, com exame sistemático, macro e microscópico, de todos os órgãos. Os encéfalos foram examinados 20 dias após fixacão em formol a 10\%, em suspensão. Os blocos retirados para exame histológico foram incluídos em parafina, cortados à espessura de $5 \mu \mathrm{m}$ e corados rotineiramente pela hematoxilina e eosina.

Dados clínicos - Os principais dados clínicos e laboratoriais dos casos estão expressos na tabela 1. Chama atenção, na avaliação clínica, a duracão curta da doença e a existência de quadro neurológico proeminente, com sinais de envolvimento meníngeo em todos os casos, sendo que no caso número 3 estava associado comprometimento encefálico e medular, razão pela qual foi feita a suspeita clínica

Trabalho realizado no Serviço de Anatomia Patológica do Hosp. Prof. Edgard Santos, Salvador BA: * Prof. Assistente do Departamento de Patologia Aplicada e Medicina Legal (setor Patologia Aplicada), da Faculdade de Medicina da Universidade da Bahia; ** Mestrando em Patologia Humana. Bolsista da CAPES. 


Caso $\begin{gathered}\text { Idade } \\ \text { (anos) }\end{gathered}$ Sexo $\begin{gathered}\text { Duracão da } \\ \text { doença }\end{gathered}$

Cefaléia. vômitos e tremores; abolição de reflexos; hipertonia muscular; rigidez de nuca; coma.

M

4 meses

Cefaléia, dores musculares generalizadas; febre e rigidez de nuca.

3 47
25 dias

Cefaléia, fraqueza em MMII com progressão à paralisia. Abolição de reflexos; ptose palpebral à direita; distúrbios de consciência; coma.
Xantocrômico, 21 células (60\% linfócitos, raras hemácias), proteinas $92 \mathrm{mg} \%$. Exame bacteriológico negativo.

Xantocrômico, 5 células (linfócitos e hemácias); glicose $35 \mathrm{mg} \%$; proteinas $70 \mathrm{mg} \%$.

Não realizado.

Encefalomielite a vírus

Tabela 1 - Carcinomatose das meninges. Dados clinico-laboratoriais de 3 casos autopsiados: LCR = liquido cefalorraqueano; MMII = membros inferiores. 
1 Adenocarcinoma do pulmão direito.

2 Carcinoma indiferenciado do estômago.

3 Adenocarcioma vesícula biliar.

da
Linfonodos mediastinais, suprarrenal direita, leptomeninges e plexos coróides.

Linfonodos cervicais, abdominais, figado, pele, peritôneo e meninges.
$1.050 \mathrm{~g}$ Moderado, com opacificação das leptomeninges e granulosidade difusa.

$1.200 \mathrm{~g}$ Discreto, com opacificação das leptomeninges timento da duramater.

$1.300 \mathrm{~g}$ Moderado, com opacificação das lepotmeninges. e granulosidade difusa. Acentuado comprome-
Fígado e leptomeninges do encéfalo e medula espinhal. 
de encefalomielite a vírus. Nos casos em que o líquido cefalorraqueano foi examinado, havia aspecto xantocrômico e hipercelularidade com predominâncla de linfócitos e presença de hemácias; a dosagem de proteína estava elevada e a glicose em niveis abaixo do normal.

Dados anátomo-patológicos - Os principais dados anátomo-patológicos estão condensados na tabela 2 . Os aspectos macroscópicos do exame dos encéfalos foram muito semelhantes, razão pela qual serão descritos em conjunto. Havia moderado grau de achatamento das circunvoluções cerebrais, congestão meníngea e herniação bilateral do uncus, mais proeminente no caso 3. As leptomeninges apresentavam apenas discreto a moderado grau de espessamento, com opacificação e uma granulosidade fina e difusa, comprometendo principalmente as superfícies convexas dos hemisférios cerebrais, pólos temporais, face orbitária dos lobos frontais e hemisférios cerebelares. O caso 2 mostrava, ainda, acentuado comprometimento neoplásico da face interna da duramater, formando uma membrana com espessura de $0,2 \mathrm{~cm}$, ao lado de extensa hemorragia recente (Fig. 1). Em nenhum dos casos havia comprometimento neoplásico da substância nervosa.

Exceto pelo aspecto histológico da neoplasia, o exame microscópico mostrou alteraçōes muito semelhantes. Nos 3 casos era proeminente o envolvimento difuso do espaco subaracnoideano pela neoplasia (Fig. 2). Nos casos 1 e 3 a neoplasia estava representada por adenocarcinoma bem diferenciado. A medula espinhal, examinada neste último caso, mostrava também comprometimento restrito às meninges, porém com neoplasia apresentando menor grau de diferenciação. No caso 2, o tumor estava representado por carcinoma indiferenciado que ultrapassava o espaco subaracnoideano, atingindo a superfície dessa membrana (Fig. 3). A duramater neste caso mostrava,

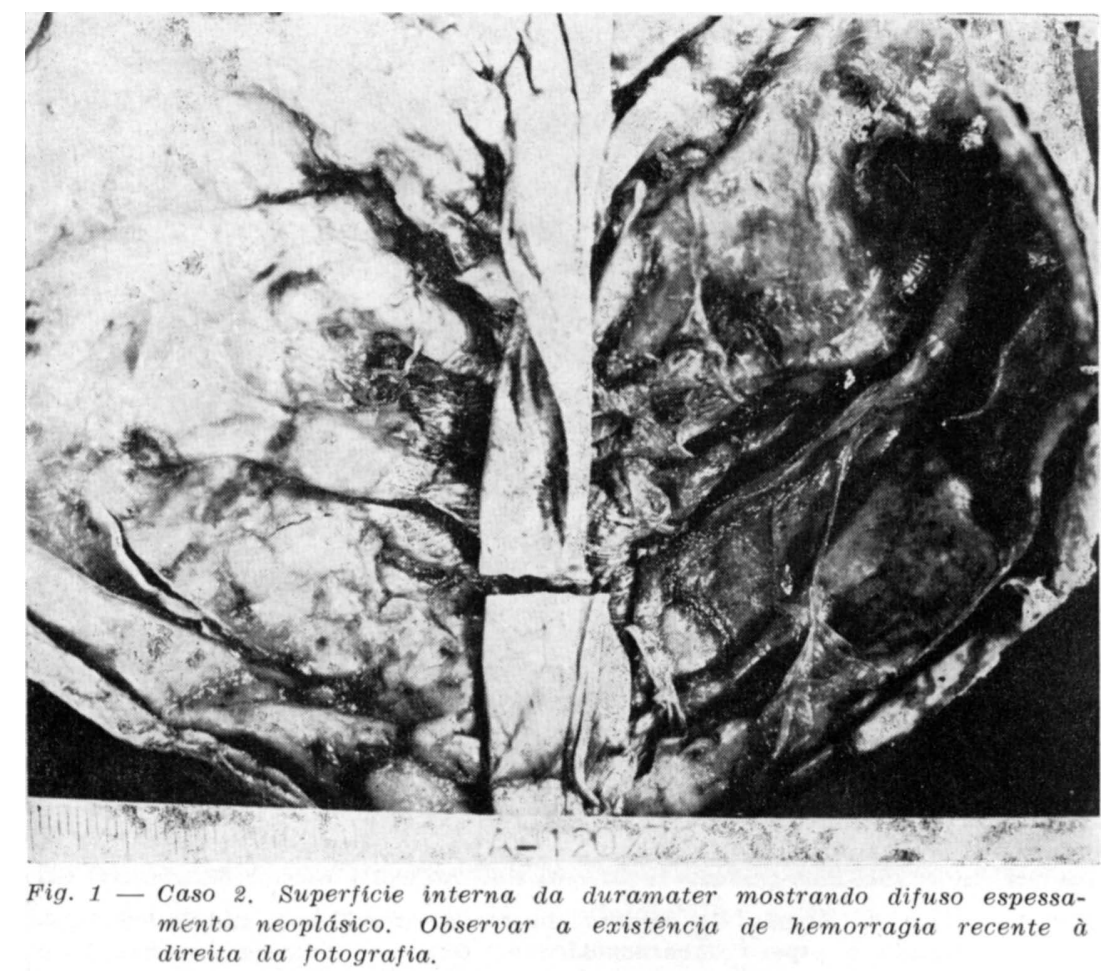




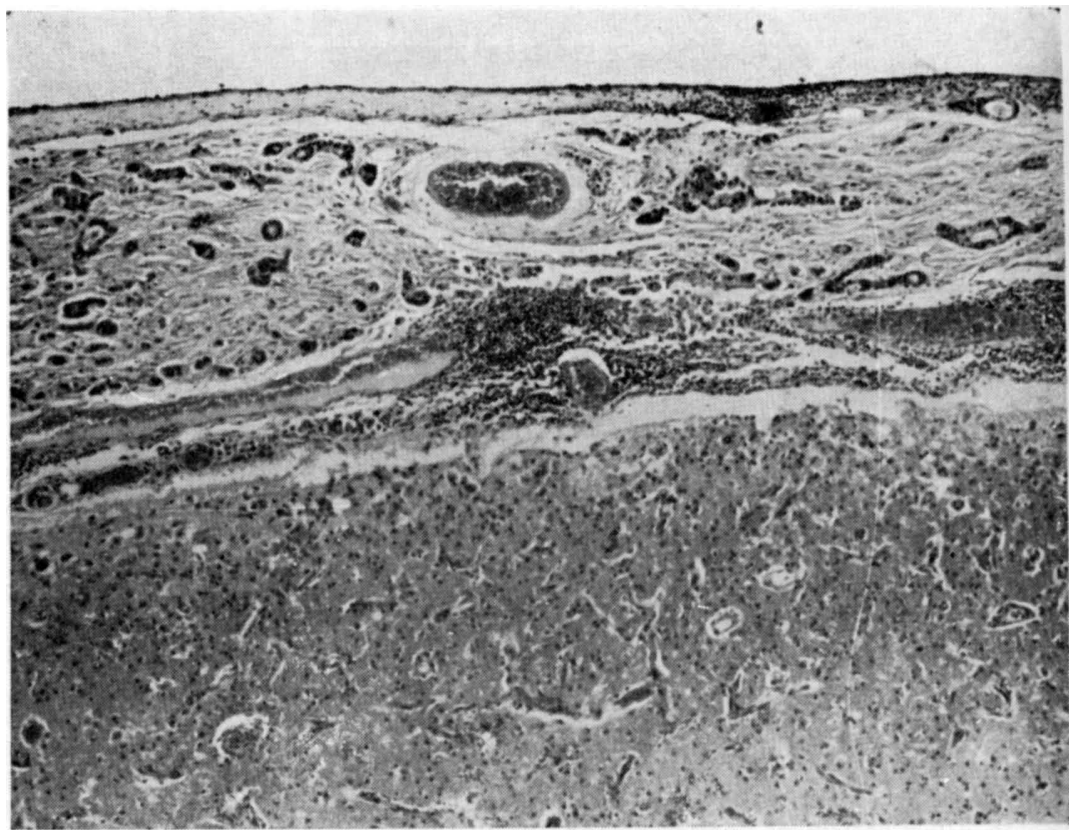

Fig. 2 - Caso 3. Secção de cérebro mostrando infiltração do espaço subaracnoideano por adenocarcinoma bem diferenciado, ao lado de focos de infiltração linfocitária (H.E. $x$ \% $)$.

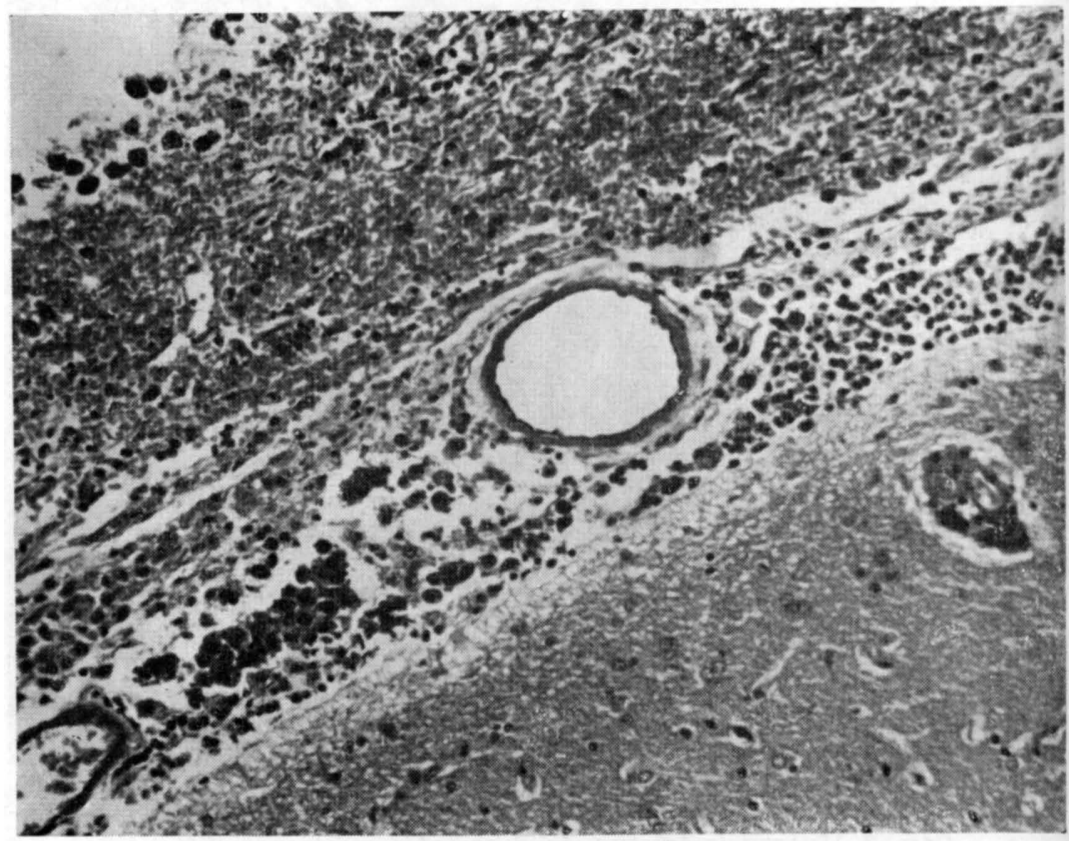

Fig. 3 - Caso 2. Secção de cérebro mostrando carcinoma anaplásico infiltrando o espaço subaracnoideano. Observar extensa hemorragia $e$ células neoplásicas recobrindo a camada aracnóide (H.E. $x$ 140). 
além do acentuado comprometimento neoplásico da face interna, proeminente dilatacão capilar na camada areolar (Fig. 4). Em todos os casos existia associado ao crescimento neoplásico, difusa infiltração linfo e histiocitária no espaço subaracnoideano.

O comprometimento dos plexos coróides foi visto em apenas um caso. A neoplasia formava pequenos nódulos no eixo conjuntivo das vilosidades, bem como na superficie epitelial.

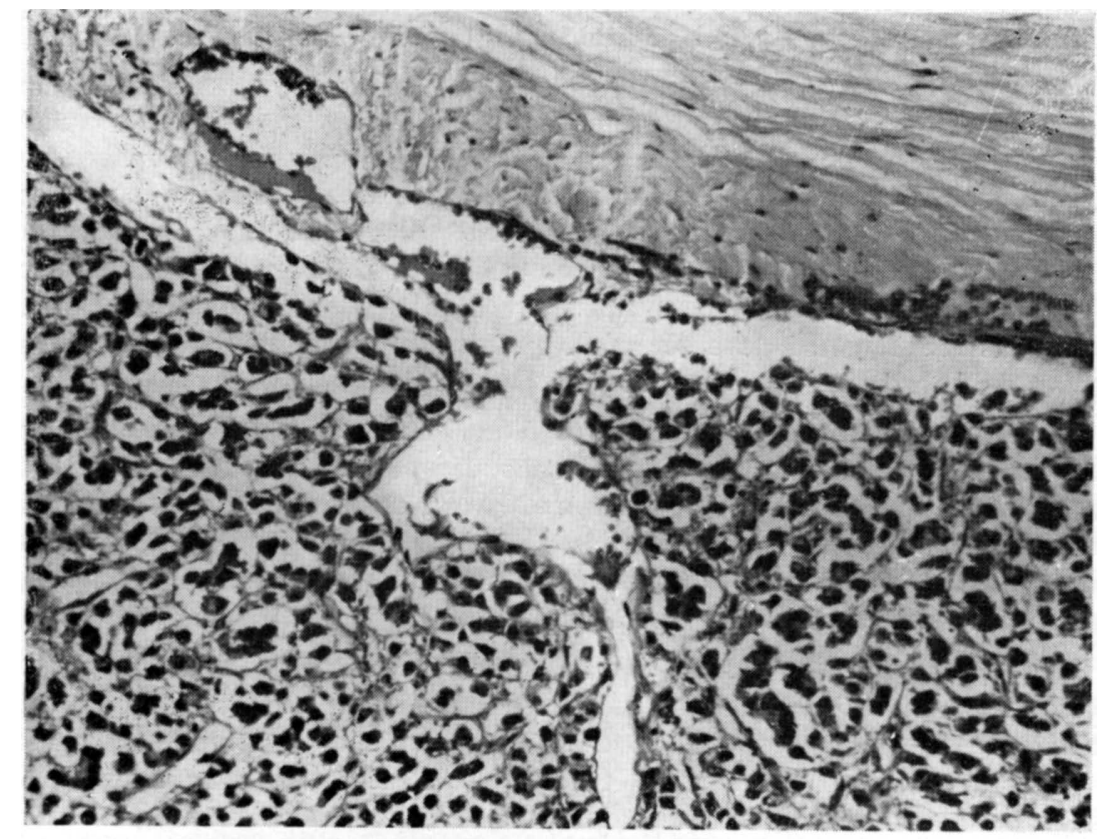

Fig. 4 - Caso 2. Secção da duramater mostrando capilares dilatados na camada areolar, ao lado de extenso crescimento neoplásico da face interna (H.E. $x$ 140).

\section{COMENTARIOS}

$\mathrm{O}$ aspecto mais interessante do ponto de vista clínico foi o quadro de envolvimento meníngeo e encefálico. Dois dos pacientes apresentaram, como sintomatologia inicial, quadro neurológico simulando meningite crônica, a ponto de terem sido considerados como sofredores de meningite tuberculosa. Este é o tipo de apresentação clínica descrito com maior freqüência ${ }^{14}, 17$, embora em alguns casos exista um quađro psiquiátrico, com sinais de confusão mental ou mesmo demência ${ }^{6,10}$. Um tipo de apresentação clínica mais raro, foi observado no caso número 3 , no qual a sintomatologia neurológica sugeria o comprometimento do tecido nervoso encefálico e medular, a ponto de ter sido considerado o diagnóstico de encefalomielite a vírus. 
Interessante observar a discrepância que existe entre o quadro clínico e os dados de macroscopia. Apesar do quadro clínico proeminente, os dados anátomo-patológicos vistos na macroscopia não foram correspondentes. $O$ envolvimento meníngeo foi apenas moderado nos casos 1 e 3 , enquanto que no caso 2 as alterações das leptomeninges foram mais discretas ainda. Neste último caso, entretanto, havia extenso comprometimento da duramater que, ao lado do crescimento neoplásico, mostrava hemorragia recente e antiga na superfície interna, com proeminente ectasia capilar na camada areolar. A associação de hemorragia subdural com carcinomatose das meninges tem sido relacionada diretamente com a dilatação capilar da camada areolar da duramater, lesão que parece ser determinada pela obstrução da circulação da duramater pela invasão tumoral ${ }^{15}$. Esta hemorragia tem sido também atribuída ao envolvimento direto desta membrana pela neoplasia ${ }^{3}$.

Em nenhum dos casos, foram vistos nódulos neoplásicos na substância nervosa, estando o comprometimento tumoral restrito ao espaço subaracnoideano, quando muito atingindo o espaço subdural, como no caso 2. Interessante a observação deste aspecto, pois para alguns autores ${ }^{8}$ o termo carcinomatose das meninges só deve ser empregado na ausência total do comprometimento da substância nervosa por nódulos neoplásicos.

O comprometimento dos plexos coróides, como visto no caso 1 , representa um dos mecanismos de disseminação das células neoplásicas que atingem as meninges. Segundo Brucher e Cervos-Navarro ${ }^{4}$, as células implantadas inicialmente nos plexos coróides por via hematogênica, descamariam para o liquido cefalorraqueano, com possibilidade de localização ao longo do espaço subaracnoideano e subdural.

Nos casos em que o líquido cefalorraqueano foi examinado, havia aumento de proteinas, hipercelularidade com linfocitose, além de aspecto xantocrômico e de hipoglicorraquia no caso 2. Estes dados, embora inespecíficos, são descritos com freqüência em casos de carcinomatose das meninges ${ }^{2,}$ ?. E com base nos dados clínicos e laboratoriais, simulando meningite tuberculosa, que alguns autores preferem o termo meningite carcinomatosa ${ }^{1,16}$. Embora nos casos aqui estudados não fossem vistas células neoplásicas no líquido cefalorraqueano, estas devem ser pesquisadas, pois representam o único elemento de certeza para o diagnóstico clínico-laboratorial desta condição.

Pela sua apresentação clínica e laboratorial, bem como pelos aspectos anátomo-patológicos, esta condição deve ser considerada como uma entidade bem caracterizada. O reconhecimento da mesma reveste-se de grande importância, pois apesar de não existir tratamento específico, os pacientes podem ter sobrevida prolongada com o uso de radioterapia e beneficiar-se com o uso de corticosteróides ${ }^{16}$.

\section{RESUMO}

Foram estudados 3 casos de carcinomatose das meninges, autopsiados no serviço de Anatomia Patológica do Hospital Prof. Edgard Santos. O quadro neurológico apresentado era proeminente e representado por sinto- 
matologia decorrente do envolvimento meníngeo e encefálico, razão pela qual foram considerados como portadores de meningite tuberculosa e encefalomielite. O aspecto de maior interesse neste estudo foi a discrepância entre o quadro clínico e os dados anátomo-patológicos do exame do encéfalo. A sintomatologia clínica foi proeminente, enquanto as lesões anatômicas foram apenas discretas ou moderadas e representadas por espessamento e granulosidade das meninges, com infiltração difusa do espaço subaracnoideano pela neoplasia. Nos casos 1 e 3 a neoplasia estava representada por adenocarcinoma, cujos focos primitivos foram localizados no pulmão e vesícula biliar, respectivamente. $O$ caso 2 era um carcinoma indiferenciado do estômago, com envolvimento difuso do espaço subaracnoideano e subdural, havendo neste último extensa hemorragia recente. Os critérios diagnósticos e a maneira de disseminação desta condição são discutidos.

\section{SUMMARY}

\section{Carcinomatosis of the meninges: a report of three cases}

A diffuse involvement of the meninges by carcinoma is described in three cases characterizing the so called "meningeal carcinomatosis". The neurologic symptoms were those of the chronic meningitis or encephalomyelitis, with changes in the spinal fluid. The morphologic features were identical in the three cases and represented by slight to moderate thickening of the meninges by diffuse infiltration of tumor cells and few foci of inflamatory reaction. The cases 1 and 3 were represented by well differentiated adenocarcinoma with primary site in the lung and gallbladder, respectively. In case 2 the tumor was a poorly differentiated carcinoma of stomach with diffuse involvement of the arachnoid and dura mater associated with recent hemorrhage. An interesting point was the lack of correlation between clinical and pathological findings. The clinical symptoms were very prominent and the gross findings only slight to moderate. The criteria for diagnosis of this entity as well as the mechanism of dissemination of the carcinoma to the meninges are reviewed and discussed.

\section{REFERENCIAS}

1. AlAJOUANine, T.; BOUdiN, G. \& CONTAMIN, J. N. - Polyradiculonéurite généralisée rapidement mortelle; méningite cancéreuse et infiltration directe des racines au contact des méninges malades. Rev. Neurol. (Paris) 82:40, 1950.

2. BERG, L. - Central nervous system disease characterized by low spinal fluid sugar. Amer. J. Medicine 20:275, 1956.

3. BRAUN, E. M.; BURGER, L. J. \& SCHLANG, H. A. - Subdural hematoma from metastatic malignant disease. Cancer 32:1370, 1973.

4. BRUCHER, J. M. \& CERVOS-NAVARRO, J. - La carcinomatose méningée. Etude anatomoclinique de 11 cas. Acta Neurol. et Psychiat. Belgica 60:368, 1960.

5. CRUZ, O. R. - Carcinomatose das meninges. Arq. Neuro-Psiquiat. (São Paulo) 17:61, 1959.

6. DAUM, S. \& FOULIN, J. F. - Les tumeurs diffuses des leptomeninges. Rev. Neurol, (Paris) 108:597, 1963. 
7. DODGE, H. W.; SVIEN, H. J. \& SAYRE, G. P. - Cerebrospinal fluid in diffuse neoplastic involvement of the meninges. Proc. Staff Meetings Mayo Clinic 27:259, 1952.

8. FISCHER-WILlIAMS, M.; BOSANQUET, F. D. \& DANIEL, P. M. - Carcinomatosis of the meninges: a report of three cases. Brain 78:42, 1955.

9. GOLDING, D. N. - Secondary adenocarcinoma of the meninges presenting with pain in the back. British J. Clinical Practice 23:299, 1969.

10. MADOW, L. \& ALPERS, B. J. - Encephalitic form of metastatic carcinoma. Arch. Neurol. Psychiat. (Chicago) 65:161, 1951.

11. MEISSNER, G. F. - Carcinoma of the stomach with meningeal carcinosis. Report of four cases. Cancer 6:313, 1953.

12. PLAUT, A. - Diffuse spinal-meningeal metastases from paranasal carcinoma. J. Neuropathology Exper. Neurol. 13:385, 1954.

13. REBUCCI, G. G. \& COCCAGNA, G. - La carcinomatosi meningea. A proposito di 4 osservazioni anatomo-cliniche. Giornale di Psichiat. Neuropatol. 90:409, 1963.

14. ROGERS, D. E. \& MCDERMOTT, W. - Neoplastic involvement of the meninges with low cerebrospinal fluid glucose concentrations simulating tuberculous meningitis. Amer. Rev. Tuberculosis 69:1029, 1954.

15. RUSSEL, D. S. \& CAIRNS, H. - Subdural false membrane or haematoma (pachymeningitis interna haemorrhagica) in carcinomatosis and sarcomatosis of the dura mater. Brain 57:32, 1934.

16. SIGWALD, J.; AJURIAGUERRA, J.; BOUTTIER, D. \& MLLE. HÉBERT Méningite carcinomateuse secondaire a un cancer du sein. Rev. Neurol. (Paris) $96: 286,1957$.

17. VITAL, C.; BRUNO-MARTIN, F.; HENRY P.; BERGOUIGNAN, M. \& LÉGER, H. - La carcinomatose méningée. Bordeaux Méd, 3:2927, 1970.

Hospital Prof. Edgar Santos - Faculdade de Medicina, Universidade Federal da Bahia - Servico de Anatomia Patológica - 40000 Salvador BA - Brasil. 